\title{
Avaliação da qualidade microbiológica da água do açude Engenheiro Ávidos, Cajazeiras-PB
}

\section{Quality Assessment of microbiological reservoir water Engenheiro Ávidos, Cajazeiras- $\boldsymbol{P B}$}

\author{
Ana Emília Formiga Marques ${ }^{1}$ Thalita Sévia Soares de Almeida ${ }^{2}$, Alfredina dos Santos Araújo ${ }^{3}$, Evencio Antonio de Sousa \\ Filho $^{4}$, Ana Carolina Brito Vieira ${ }^{5}$
}

Resumo: A água é um recurso renovável de extrema importância para sobrevivência e manutenção das espécies, assim como preservação da fauna e flora. Nos últimos anos o homem vem modificando o ecossistema, através do desmatamento e crescimento dos centros urbanos que causam diferentes tipos de poluição, causando um grande desperdício e contaminação da água. Nesse contexto, é essencial conhecer a qualidade da água que é consumida em uma cidade. Por isto, neste trabalho, objetivou-se realizar uma avaliação da qualidade bacteriológica da água do açude Engenheiro Ávidos que abastece a cidade de Cajazeiras - PB. O trabalho foi realizado através de estudo aplicado do tipo exploratório quantitativo, no qual foi analisada a presença de bactérias heterotróficas a partir de contaminação fecal, ou seja, esgotos não tratados. Foram coletadas três amostras em diferentes pontos do açude, sendo estes: entrada do açude, proximidade das habitações e paredão. Após análise foi possível identificar que o açude Engenheiro Ávidos encontra-se dentro dos parâmetros exigidos pelo CONAMA, uma vez que apresentou 150 (entrada do açude), 30 (habitações) e 0 (no paredão) coliformes a cada 100 mL de água, identificando ainda sim, uma elevação na quantidade de micro-rganismos na região da entrada do açude, o que pode ser explicado pela proximidade com a cidade de São José de Piranhas e possíveis esgotos. Nesse contexto é enfatizada a importância do monitoramento das águas que são destinadas, principalmente, ao consumo humano, atuando de forma preventiva sobre contaminações ao homem.

Palavras-chaves: Qualidade de água. Microbiologia. Coliforme fecal.

\begin{abstract}
The water is a renewable resource of paramount importance for the survival and maintenance of the species, as well as preservation of fauna and flora. In recent years man has been changing the ecosystem, through deforestation and growth of urban centers causing different types of pollution, causing a great waste and water contamination. In this context, it is essential to know the quality of water that is consumed in a city. Therefore, this study aimed to carry out an assessment of the bacteriological water quality of the weir Engenheiro Avidos that supplies the city of Cajazeiras - PB. The work was performed by the quantitative study applied exploratory, in which they analyzed the presence of heterotrophic bacteria from fecal contamination, in other words, untreated sewage. Three samples were collected at different points of the weir, these being: intake weir, proximity to housing and seawall. After analysis it was identified that the weir Engenheiro Avidos is within the parameters required by CONAMA, since were identified 150 (intake weir), 30 (housing) and 0 (the breakwater) coliforms per $100 \mathrm{ml}$ of water, while also being among the values allowed by CONAMA, identifying yet, an elevation the amount of microorganisms in the intake weir, which can be explained by the proximity to the town of São José de Piranhas and possible sewage. In this context is emphasized the importance of water quality monitoring that are designed primarily for human consumption, acting preventively about contamination to man.
\end{abstract}

Keywords: Quality of water. Microbiology. Fecal coliform.

\footnotetext{
*Autor para correspondência

Recebido para publicação em 18/11/2015; aprovado em 20/12/2015

${ }^{1}$ Mestranda em Ciências Naturais, Universidade Federal de Campina Grande, Cuité - PB, E-mail: anaemiliaformiga@hotmail.com

${ }^{2}$ Mestre em Sistemas Agroindustriais, Universidade Federal de Campina Grande, Pombal - PB, E-mail: thalitasevia22@ gmail.com

${ }^{3}$ Professora CCTA-PPGSA, Pombal - PB, e-mail: alfredina@ ccta.ufcg.edu.br

${ }^{4}$ Especialista em Análises Clínicas, Faculdade Leão Sampaio, Juazeiro do Norte - CE, E-mail: evencio_antonio@hotmail.com

${ }^{5}$ Doutoranda em Ciências Biológicas, Universidade Federal da Paraíba, João pessoa - PB, E-mail: ac.brito@hotmail.com
} 


\section{INTRODUÇÃO}

A presença de água no planeta é fator determinante para a existência de vida nele. A água é um recurso natural de valor inestimável para o homem, uma vez que é utilizada nas atividades de produção como indústria, lazer, recreação, além de participar das reações bioquímicas, manutenção dos ciclos geológicos, biológicos, químicos, manutenção do ecossistema, preservação da fauna e flora. As águas que fazem parte do consumo para a sociedade são recursos hídricos, como: rios, lagos, represas e aquíferos (águas interiores) (ANDRAUS, 2006).

O Brasil, devido a sua localização é um país privilegiado em recursos hídricos, uma vez que possui $12 \%$ da disponibilidade mundial de recursos hídricos, o que corresponde a uma vazão média anual dos rios em cerca de $180 \mathrm{mil} \mathrm{m} 3 / \mathrm{s}$, isso se forem levadas em conta as vazões oriundas em território estrangeiro e que ingressam no país (Amazônica: $86.321 \mathrm{mil} \mathrm{m}^{3} / \mathrm{s}$ ) (MARENGO, 2008).

Nas últimas décadas, os ecossistemas têm sido modificados em grandes escalas, essas modificações, conforme Pereira (2004) tem causado diversas complicações, principalmente pelo uso da água de forma descontrolada e o grande desperdício o que causa uma diminuição da disponibilidade de água de qualidade, gerando poluentes que são prejudiciais à saúde do homem.

A contaminação da água se dá por presença de microrganismos, substâncias químicas e/ou resíduos do meio ambiente, as fontes de contaminação, segundo Pereira (2004) são classificadas em: tópicas ou fixas que são as contaminações que ocorrem em um ponto fixo e as difusas que são contaminações afastadas das fontes aquáticas, não possui uma fonte única de contaminação, como veículos automotores, zonas residenciais, industriais, esgotos domésticos, entre outros.

Os fatores de poluição dividem-se em naturais, os que são causados pela natureza, como tempestades, queimadas e etc. E artificiais que são causadas pelos o homem através do desmatamento e crescimento dos centros urbanos, ou do uso irracional da água.

A potabilidade da água refere-se da utilização da metodologia de avaliação quantitativa de risco microbiológico, que define do padrão de turbidez da água filtrada, como indicador da remoção de protozoários, e dos parâmetros de controle da desinfecção, indicadores da inativação de bactérias, vírus e protozoários (CÂMARA, 2007).

A água, para que seja apta para o consumo humano, passa por um teste de controle qualidade, o qual vai definir se ela estiver no padrão de turbidez, além dos parâmetros microbiológicos, físicos, químicos, e radioativo (BRASIL, 2004).Os corpos d'água que não apresenta nenhuma alteração e que não provoque risco à saúde do homem, que esteja nos parâmetros exigidos, são e podem ser considerado como potável.

O Conselho Nacional do Meio Ambiente (CONAMA) padroniza os valores máximos que podem ser encontrados de coliformes fecais e outros microrganismos para que a água seja considerada potável. De acordo com essa padronização, os microrganismos indicadores que devem ser pesquisados são: os coliformes termotolerantes, Escherichia coli e Enterococo (BRASIL, 2012).
Percebe-se, portanto a importância de identificar a qualidade da água do açude que abastece a cidade de Cajazeiras, uma vez que a realização do estudo possibilitará o conhecimento do comportamento sobre a qualidade da água do açude Engenheiro Ávidos e, dessa forma, poderá subsidiar ações de prevenir e controle de poluição de água na cidade Cajazeiras - PB no contexto estudado. Nesse contexto, este trabalho objetiva avaliar espacialmente a qualidade bacteriológica da água do açude Engenheiro Ávidos, reservatório que abastece a cidade de Cajazeiras.

\section{MATERIAL E MÉTODOS}

Para o presente estudo, foi realizada uma pesquisa de natureza aplicada, exploratória operacional, através de coletas em campo e procedimentos laboratoriais e quantitativa no Açude Engenheiro Ávidos que está localizado na Bacia Piranhas no alto sertão Paraibano, sendo responsável por abastecer toda a cidade de Cajazeiras e região.

Por se tratar de uma avaliação espacial preliminar, foi feita uma única coleta, abrangendo diferentes regiões do reservatório. $\mathrm{Na}$ entrada do rio, na região da margem, próximo a habitações de pescadores ribeirinhos, e o último na barragem. Em campo foram analisados os seguintes parâmetros: Oxigênio dissolvido e Temperatura, através do oxímetro digital da marca HandLab; pH através de peagâmetro digital da marca Incoterm.

Para as análises microbiológicas, as amostras de água foram coletadas em frascos esterilizados apropriados. Foi feito a determinação da presença de coliformes totais e fecais. Para isso, as análises de presença de coliformes totais foram feita a técnica dos Tubos Múltiplos com Caldo Lactosado. Após isso, foi feita a confirmação para coliformes totais pela técnica de Pour Plate pelo Meio McConkey.

Em seguida foram feitas as análises de estatística descritiva, da qual foi realizada a comparação a fim de se saber quais os locais do açude mais contaminado, com posterior investigação sobre as possíveis causas.

\section{RESULTADOS E DISCUSSÃO}

Para a verificação da qualidade microbiológica da água do açude Engenheiro Ávidos, quanto às suas características ambientais e às comunidades microbiológicas, foram adotados os padrões estabelecidos pela Resolução n ${ }^{\circ} 357$ de 18 de março de 2005 do Conselho Nacional de Meio que regulamenta a classificação de corpos d'água de acordo com seu uso. (BRASIL, 2005).

Dessa forma, foram coletadas amostras de três pontos com frascos estéreis próprios para coleta. Os pontos escolhidos foram entrada do açude, paredão e habitações, após a coleta, todos os frascos foram devidamente identificados com horário e local.

Para a contagem de bactérias foi utilizado o teste do número mais provável e o teste presuntivo. A técnica do número mais provável (TNM) permite calcular o número de um micro-organismo específico numa amostra de água, utilizando tabelas de probabilidade, que foi feito em duas etapas o teste presuntivo e o teste confirmativo.

O teste presuntivo consiste em organizar 3 séries de 3 tubos de meio de cultura seletivo de caldo Lauryl triptose, em seguida transfere-se $1 \mathrm{ml}$ de uma amostra ou diluição decimal 
de uma amostra para 3 ou mais tubos de caldo verde brilhante, incuba os tubos por $24 \pm 2$ horas à $35^{\circ} \pm 1^{\circ} \mathrm{C}$, e observa se ocorreu produção de gás e aprisionamento deste nos tubos de Durham.

Esse teste, de acordo com estudo realizado pela UNESP (2010), permite observar a existência de coliformes na água, mas não é possível afirmar se esses coliformes são fecais. Por isso a importância da realização do teste confirmativo, uma fez que o caldo Lauryl triptose favorece o crescimento de micro-organismos sem inibir o crescimento de bactérias entéricas.

Após a realização do teste foi anotado os resultados e feito o teste confirmativo para os tubos que tiveram resultados positivos. Os tubos que deram negativo foram incubados por mais 24 horas e foi refeita a leitura

Nessa primeira fase, foi possível determinar uma estimativa preliminar da densidade do grupo bacteriano baseado no enriquecimento em um meio restritivo, do qual foi possível observar os seguintes valores (Tabela 1).

Tabela 1. Resultados do Teste presuntivo registrados em diferentes regiões do açude.

\begin{tabular}{lcccc} 
& 01:01 & 01:100 & $\mathbf{1 : 1 0 0 0}$ & NMP/100ml \\
Entrada & 5 & 4 & 2 & 220 \\
Habitações & 5 & 3 & 1 & 110 \\
Paredão & 4 & 2 & 1 & 26 \\
\hline
\end{tabular}

Após o teste presuntivo, foi feita a inoculação em placas com o Meio McConckey, que confirmou presença de E. coli na entrada e na habitação, mas que esses valores não excedem o limite estabelecido pelos padrões do CONAMA, essa diferença entre as regiões pode ser causada pela proximidade com a cidade de São José de Piranhas, o que pode haver lançamentos de esgotos, aumentando assim a presença de bactérias (Tabela 2).

Tabela 2. Resultados do teste confirmativo para a presença de E. coli, no Meio McConckey.

\begin{tabular}{lccc} 
Escherichia & UFC/100ml & UFC/100ml & UFC/100ml \\
coli & $(\mathbf{1 : 1 )}$ & $(\mathbf{1 : 1 0 0 )}$ & $(\mathbf{1 : 1 0 0 0 )}$ \\
Entrada & 150 & 20 & 0 \\
Habitações & 30 & 0 & 0 \\
Paredão & 0 & 0 & 0 \\
\hline
\end{tabular}

Esses resultados estão condizentes com resultados encontrados nos estudos realizados por Lima; Garcia (2008), o qual identificou maior quantidade de micro-organismos no período da seca e associou este fator a diminuição do volume e não renovação da água, que ocasiona uma maior concentração de coliformes, já que se torna menor a diluição.

Quando comparados a estudos realizados por Sperling et al. (2009), esses valores são inferiores uma vez neste, do qual foi identificado 240 coliformes a cada 100 mililitros de água, sendo nesse caso a água considerada imprópria para o consumo humano.

Os valores limites de micro-organismos presente nos corpos de água classe 3 é definido pela CONAMA, sendo estes: para o uso de recreação de contato secundário não deverá ser excedido um limite de 2500 coliformes termotolerantes por 100 mililitros em $80 \%$ ou mais de pelo menos 6 amostras, coletadas durante o período de um ano, com frequência bimestral. Para dessedentação de animais criados confinados não deverá ser excedido o limite de 1000 coliformes termotolerantes por 100 mililitros em $80 \%$ ou mais de pelo menos 6 amostras, coletadas durante o período de um ano, com frequência bimestral. Para os demais usos, não deverá ser excedido um limite de 4000 coliformes termotolerantes por 100 mililitros em $80 \%$ ou mais de pelo menos 6 amostras coletadas durante o período de um ano, com periodicidade bimestral. A E. Coli poderá ser determinada em substituição aos parâmetros coliformes termotolerantes de acordo com limites estabelecidos pelo órgão ambiental competente. (BRASIL, 2005)

Assim sendo, a partir dos testes realizados, foi possível observar que o Açude Engenheiro Ávidos encontra-se, quanto à presença de micro-organismos, entre os parâmetros estabelecidos pela CONAMA.

\section{CONCLUSÃO}

Ao realizar a avaliação de micro-organismos do açude, percebe-se que o mesmo encontra-se dentro do limite permitido pelo CONAMA, porém há uma alteração na região próxima a entrada do açude, o qual pode ser explicado pela proximidade com a cidade de São José de Piranhas, e a possibilidade de existência de esgotos nessa região.

Tendo em vista a qualidade microbiológica da água, podem ser realizadas políticas públicas, objetivando a sensibilização da comunidade quanto à importância da água e da necessidade de preservação, assim como adotar medidas para melhoramento da qualidade de água, tais como: melhoria de instalações de bombeamento de água e sistemas de tratamento de esgoto; sistema para detecção e diagnóstico de vazamentos em redes de distribuição de água; sistema de filtração de água e tecnologias para remoção, tratamento e disposição de lodos extraídos de estações de tratamento; monitoramento da carga de patógenos nos esgotos e gestão sustentável de recursos hídricos pela investigação dos efeitos na agricultura e no ambiente do uso de esgoto tratado para irrigação de culturas.

Esse estudo é de fundamental importância, uma vez que possibilita o monitoramento da qualidade das águas, permitindo assim a identificação, análise e prevenção de problemas, agindo de forma a melhorar a condição ambiental do açude Engenheiro Ávida.

\section{REFERÊNCIAS BIBLIOGRÁFICAS}

ANDRAUS, S. Aspectos microbiológicos da qualidade sanitária das águas do mar e areias das praias de Matinhos, Caiobá e Guaratuba-PR. Dissertação (Mestrado em Ciência do Solo) - Pós-Graduação em Ciência do Solo Universidade Federal do Pará, Curitiba, 2006.

BRASIL. IDB 2008. Indicadores e Dados Básicos para a Saúde, 2008. Disponível em: http://tabnet.datasus.gov.br/cgi/idb2008/matriz.htm Acesso em 01 dez. 2013.

BRASIL, Instituto Brasileiro do Meio Ambiente e dos Recursos Naturais Renováveis. Resoluções do Conama: Resoluções vigentes publicadas entre setembro de 1984 e janeiro de 2012. / Ministério do Meio Ambiente. Brasília: MMA, 2012. 
CAMPELLO, F. D. A problemática da poluição por esgoto domestico no sistema Estuarino-Lagunar TramandaiArmazém (RS BRASIL): física e química da água e a resposta dos macroinvertebrados betônicos. Dissertação (Mestrado em Ecologia) - Programa de Pós-Graduação em Ecologia - Universidade Federal do Rio Grande do Sul, Porto Alegre, 2006.

MARENGO, J. A. Água e mudanças climáticas. Revista Estudos Avançados, v.22, n.63, 2008.

PEREIRA, R.S. Identificação e caracterização das fontes de poluição em sistemas hídricos. Revista Eletrônica de Recursos Hídricos, v.1, n.1, p. 20-36, 2004.

SPERLING. C. et al. Avaliação física, química e microbiológica da qualidade da agua para fins de pisicultura. In: XVIII Congresso de Iniciação Científica e I Mostra Científica, 2009. 